\title{
Competencias docentes en los lineamientos institucionales y de programa
}

\section{Teaching skills the institutional guidelines and program}

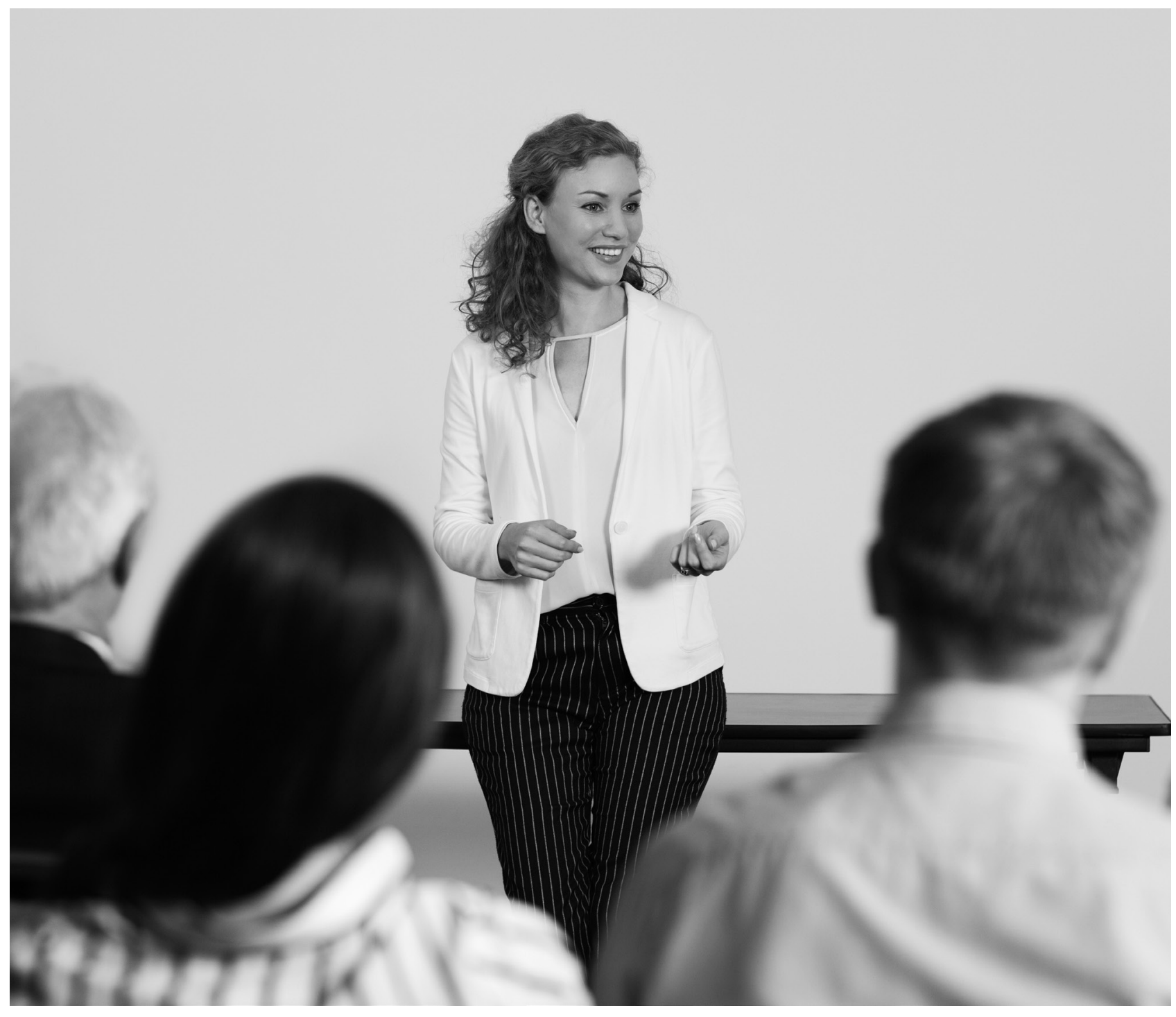




\title{
Competencias docentes en los lineamientos institucionales y de programa ${ }^{1}$
}

\section{Teaching skills the institutional guidelines and program}

\author{
Andrés Felipe Rojas Zapata, ${ }^{2}$ Isabel Hernández Arteaga ${ }^{3}$
}

Artículo recibido en agosto de 2017; artículo aceptado en marzo de 2018.

Este artículo puede compartirse bajo la Licencia Creative Commons Atribución-No Comercial-Compartir Igual 2.0 Genérica y se referencia usando el siguiente formato: Rojas, A. \& Hernández, I. (2018). Competencias docentes en los lineamientos institucionales y de programa. I+D Revista de Investigaciones, 12 (2), 27-38. DOI: https://doi.org/10.33304/revinv.v12n2-2018003

\section{Resumen}

Este artículo es resultado de investigación, cuyo objetivo es reconocer las competencias docentes presentes en los lineamientos institucionales y del programa de psicología. La metodología está orientada por los postulados cualitativos; el enfoque es hermenéutico y la investigación, interpretativa. Se realizó en dos universidades en las que se hizo revisión de tres documentos: el Proyecto Educativo Institucional, el Proyecto Educativo del Programa y el Estatuto docente, buscando las competencias docentes estipuladas en ellos. La información obtenida se ratificó con una entrevista a los docentes de los programas de psicología. Los resultados obtenidos señalan que las competencias docentes no se encuentran o se enuncian de manera concreta en los lineamientos, y los docentes desconocen su existencia en estos. Como conclusión se pudo establecer que los documentos institucionales objeto de investigación se evidencian en las instituciones y su calidad es reconocida, pero no son de conocimiento y manejo de los docentes en la formación del psicólogo.

Palabras clave: competencias docentes, proyecto educativo institucional, proyecto educativo del programa, estatuto docente, formación profesional.

\footnotetext{
Abstract

This article is result of research, its objective, recognize the present institutional guidelines and the program of Psychology teaching skills. Methodology oriented under qualitative assumptions, the hermeneutic approach and interpretative research; held at two universities, which was reviewing three documents: the institutional education project, the educational project of the program and teaching status, looking for teaching competencies stipulated therein; confirming this information with interview with teachers of Psychology programs. Results, teaching

1. Artículo de resultados de investigación, cualitativo, Resultado de un proyecto de investigación finalizado, perteneciente al área de Psicología, desarrollado por los Grupos de Investigación CIDU de la Universidad Cooperativa de Colombia, cofinanciado por la Universidad Cooperativa de Colombia y la Universidad de Nariño. Fecha de inicio: enero 2015. Fecha de terminación: diciembre de 2016.

2. Psicólogo, Universidad de Nariño. Magister en Docencia Universitaria, Universidad de Nariño. Docente tiempo completo, programa de Administración en Salud Ocupacional, Corporación Universitaria Minuto de Dios - Centro Regional Pasto; Investigador del Grupo Convivencia y Entornos Psicológicos CONEPSI, de la Universidad de Nariño de la ciudad de Pasto, Colombia. ORCID ID: https://orcid.org/0000-0001-8275-3396. Correo electrónico: andresps0707@hotmail.com.

3. Doctora en Ciencias de la Educación, posdoctora en Investigación Cualitativa. Docente Investigadora del Grupo CIDU de la Facultad de Educación en el nivel de Posgrados de la Universidad Cooperativa de Colombia sede Bogotá. ORCID ID: https://orcid.org/0000-0002-6299-0236. Correo electrónico institucional: Isabel.hernandez@ucc.edu.co.
} 
competencies are missing or set forth in a very general way in guidelines and teachers are unaware of its existence in them. Conclusion, institutional documents under investigation, are evident in the institutions and is recognized for its quality but are not of knowledge and management of teachers in the formation of the psychologist.

Keywords: teaching skills, institutional educational project, educational project of the program, teaching status, vocational training.

\section{Introducción}

En la sociedad actual es evidente la necesidad de que las Instituciones de Educación Superior (IES) y los docentes universitarios sean capaces de orientar la formación de profesionales para responder de manera creativa, innovadora y pertinente a las necesidades manifiestas de un mundo globalizado, que, como lo mencionan Hernández, Alvarado y Luna (2015), se caracteriza por ser inseguro, incierto y estar en constante transformación.

De otra parte, conviene tener presentes los argumentos de Gómez y Alzate (2010), quienes consideran que el concepto de competencia es ambiguo y polisémico y está sujeto a diversos significados según el contexto en el que se utilice. Como consecuencia, de acuerdo con Irigoyen, Jiménez y Acuña (2011), es asumido como un concepto idealista que ofrece dificultades para su aplicación, evaluación, instrumentación y planeación en la educación debido a la ambigüedad respecto a su definición. Igual cosa ocurre en el proceso de formación profesional, donde se evidencia dificultad en la implementación, porque, a decir de Beata (2014), no existe correspondencia entre las calificaciones numéricas de los graduados y las competencias que requieren para desempeñarse en el mundo laboral.

Cabe resaltar que las competencias son un enfoque en la educación actual, que según Delors (1996), debe ser implementado en todos los niveles de formación, pues la educación debe enseñar a vivir mejor a las personas mediante el uso adecuado del conocimiento teórico y práctico, pertinente y útil para toda la vida, a través de la experimentación y el desarrollo integral y cultural de la persona. Para dar cumplimiento a estos postulados Beata propone cuatro pilares de la educación en los que se organizan las competencias del saber conocer, el saber hacer, el saber ser y el saber convivir, según los cuales, considera, se deben guiar los procesos de la formación de los seres humanos siendo estos, además una meta a alcanzar en sí misma.

Para Guzmán y Gutiérrez (2017) toda institución educativa en general -y la universidad en particular- requiere que sus docentes cuenten con las competencias necesarias para su desempeño en el proceso de enseñanzaaprendizaje. Dichas competencias se equiparan, en este caso, con el conjunto de habilidades, actitudes y valores de los profesores para ejercer la labor de orientar la creación y el desarrollo del conocimiento por parte de sus estudiantes.

Para esta implementación en la universidad se requiere de profesores universitarios con competencias docentes que, de acuerdo con Morales y Cabrera (2012), independientemente de la profesión que enseñe o profese, deben poseer competencias básicas en lo que concierne a su ejercicio como educadores. Sobre este tópico, Tejada (2009) argumenta que el docente debe tener conocimiento del proceso de aprendizaje del estudiante, tanto en contextos naturales como académicos; planificación de la enseñanza e interacción didáctica; gestión de la interacción didáctica y de las relaciones con los estudiantes; control, evaluación y regulación del ejercicio docente y del aprendizaje; y debe estar al tanto de las normas legales e institucionales bajos las cuales se amparan los derechos y deberes del profesor y el estudiante.

Bragós (2012), por su parte, resalta tres grandes grupos de competencias transversales para los docentes, entre las que se señalan las competencias que implican el conocimiento teórico o disciplinar de la profesión; las competencias de razonamiento; los atributos y habilidades tanto personales como profesionales y las interpersonales. Cabe resaltar la investigación de Giné (2008) sobre las consideraciones de los estudiantes universitarios acerca del ejercicio docente, en la que destaca que el profesorado ha de ser capaz de emplear estrategias didácticas que posibiliten a los estudiantes desarrollar competencias profesionales para resolver problemas contextuales, enriquecidas con conocimientos actualizados y pertinentes a las necesidades y demandas de la profesión y de la sociedad, y que comprometan al estudiante con su aprendizaje mediante procesos reflexivos y críticos que le permitan enfrentarse de manera efectiva a nuevos retos.

En la actualidad, el enfoque educativo planteado para responder a las demandas de la sociedad es el enfoque por competencias, que, según García y González (2015), la universidad debe implementar para formar profesionales libres que le aporten a la sociedad. El enfoque de competencias es el eje central en el desarrollo 
de la investigación que dio origen a este artículo y que buscó reconocer cómo el concepto de competencias docentes es asumido en los diferentes lineamientos pedagógicos de dos universidades del departamento de Nariño, Colombia. Dichos lineamientos están registrados y han sido desarrollados en el Proyecto Educativo Institucional (PEI), en el Proyecto Educativo del Programa (PEP) y en el Estatuto docente, y se ha complementado además con el conocimiento que tienen los docentes de programas de pregrado de psicología adscritos a estas mismas instituciones, sobre cuáles son las competencias docentes recogidas por estos tres documentos institucionales.

No obstante, existen docentes o administrativos que se resisten a formar parte activa del enfoque por competencias y de las políticas institucionales. Atendiendo a Morín (2007), el cambio de paradigma implica no solo cambiar la metodología de trabajo, sino que es más complicado que eso ya que tiene que ver con la manera en que el docente percibe la realidad. Más aún, las IES deben hacer conciencia sobre cómo perciben su realidad, el contexto al que pertenecen y el mundo que está más allá, para asumir la responsabilidad de sus acciones en la formación de profesionales competentes.

Por su parte, Beneitone et al. (2007) manifiestan la necesidad que existe en las IES de América Latina de implementar en su actuar pedagógico el enfoque por competencias, esto debido al desarrollo social y económico enfocado hacia la productividad con base en el conocimiento y el manejo de la información que se crea y reproduce de manera vertiginosa. Para cumplir con este propósito, las IES requieren ampliar su visión educativa para el mundo del siglo XXI y lograr las condiciones necesarias en todas sus áreas para que sea factible la implementación adecuada de este enfoque en los programas académicos. Cabe destacar como un tema principal las competencias del docente, en tanto elemento cardinal en la formación de profesionales (Camelo, 2014).

En programas académicos como Psicología, los docentes no cuentan con formación pedagógica y carecen de competencias docentes, hecho que dificulta la implementación del enfoque en la formación del psicólogo. Dice Salgado (2006) que ser un experto en una disciplina no necesariamente implica tener las competencias docentes para orientar el logro de las competencias del estudiante o enseñar ese mismo saber. Según el Ministerio de Educación Nacional [MEN] (2014), el docente tiene tres ejes fundamentales para planear la enseñanza: primero, conocimiento en el área de investigación para fortalecer el conocimiento disciplinar y pedagógico articulando teoría y práctica; segundo, conocimiento de procesos lecto-escritores y enseñanza sobre la profesión específica; y tercero, políticas educativas estatales e institucionales para acercarse a los elementos que regulan su ejercicio profesional.

El docente universitario, en particular el docente de programas de Psicología, debe estar abierto al cambio de paradigma que le permita una visión amplia del mundo, una concepción dinámica de la educación y un proceso de enseñanza-aprendizaje en el que cumple la función de orientar el logro de competencias del estudiante. Para Hernández, Recalde y Luna (2015) la docencia es intencional, evoluciona dependiendo de los contextos y las perspectivas donde se utiliza, donde no es pertinente la transmisión de conocimientos sino la orientación del logro de competencias.

\section{Método}

\section{Tipo de estudio}

La investigación se desarrolló siguiendo lineamientos del paradigma cualitativo, que, a decir de Bonilla y Rodríguez (1997), pretende acercarse a una realidad social para explorarla, describirla y analizarla basándose en la percepción subjetiva de la realidad de los sujetos que hacen parte de un contexto específico. Su utilidad radica en lo expresado por Martínez (2011), quien considera que la realidad se crea a través de la interacción del sujeto con el entorno, por lo que no se puede hablar de una sola verdad, ya que esta nace de la significación de las diferentes percepciones que los individuos obtienen de las múltiples situaciones en que se desenvuelven. En este sentido, los lineamientos pedagógicos de las IES y los docentes del programa de psicología se constituyen en la población idónea para indagar sobre las competencias docentes presentes en el PEl, PEP y el Estatuto docente, así como del conocimiento que los docentes tienen de su existencia en dichos documentos. El enfoque hermenéutico y la investigación interpretativa orientaron el proceso, pues según Vásquez (1986) se llega a la comprensión de los hechos a través de la interpretación de los sentidos, los cuales solamente se pueden estructurar a través de aquellos que obran en el contexto objeto de estudio. En efecto, dicho enfoque posibilitó la interpretación de las relaciones entre las competencias docentes estipuladas en los documentos y el conocimiento que los docentes tienen de ellas.

\section{Participantes}

La población con la que se trabajó fueron docentes de los programas de psicología de dos IES de la ciudad de Pasto, Departamento de Nariño, Colombia. Formaron parte de la muestra trece docentes que cumplieron con 
los criterios de inclusión: ser psicólogo, magister o doctor en el área de la Psicología o de las Ciencias Sociales y Humanas, tener una experiencia de mínimo tres años como docente en la institución y aceptar participar voluntariamente en el estudio.

\section{Técnicas e instrumentos}

Técnica de revisión documental. Según Arias (2006), es un proceso basado en la búsqueda, recuperación, análisis, crítica e interpretación de datos secundarios; es decir, los obtenidos y registrados en fuentes documentales. El instrumento empleado fue la Ficha de revisión, que se levantó para cada uno de los tres documentos de las instituciones $\mathrm{A}$ y $\mathrm{B}$.

Entrevista en profundidad. Gorden (1969) la concibe como una relación comunicativa tríadica entre entrevistado, entrevistador e información. Dicho instrumento permitió llegar a los trece docentes de los programas de Psicología y, de manera individual, indagar sobre su conocimiento acerca de las competencias docentes registradas en el PEI, el PEP y el Estatuto docente de cada una de sus instituciones. Los instrumentos de recolección de información fueron validados por expertos en el tema y en investigación cualitativa.

La información se sistematizó mediante el proceso de matrices de categorías inductivas y los resultados se interpretaron y comprendieron a través de la técnica de triangulación, que, según Béricat (1998), utiliza diferentes visiones sobre el objeto de estudio, siendo tres los puntos de vista para este caso en particular: la teoría previamente revisada sobre el tema, la información recolectada y el punto de vista del investigador como constructor principal de los hechos.

\section{Resultados}

\section{¿Cómo conceptualizan y asumen las competencias las IES en sus lineamientos pedagógicos?}

Para comenzar este apartado es necesario resaltar que, con la finalidad de proteger tanto la identidad de las universidades como de los docentes que decidieron ser partícipes en el presente estudio de manera libre y voluntaria, se mantendrá el anonimato, nominando las instituciones como A y B. Las IE participantes autorizaron, primero, la revisión de los tres documentos objeto de este estudio: el Proyecto Educativo Institucional (PEI), el Proyecto Educativo del Programa (PEP) y el Estatuto docente; y segundo, la participación de los docentes del programa de Psicología.

Competencias docentes en el Proyecto Educativo
Institucional (PEI), instituciones A y B.

El Ministerio de Educación Nacional (2015), en el Decreto 1075, plantea que las IES de carácter público o privado deben planear y poner en práctica el $\mathrm{PEI}$, constituyéndose este documento de lineamientos institucionales en la carta de navegación de las IES y en una estrategia que permite garantizar la idoneidad a través de la sistematización y la organización de la información que contiene. Se señala además que las IES deben contar con un cuerpo docente que garantice el cumplimiento de los objetivos de la formación; es decir, los profesores han de poseer las competencias necesarias para realizar con idoneidad su ejercicio profesional. También, en el Decreto 2566, Artículo 9, el MEN (2003) sostiene que el personal docente debe contar con formación pedagógica que le permita desarrollar satisfactoriamente sus labores en la educación superior.

Teniendo en cuenta lo anterior, la ficha de revisión documental y la matriz de categorías inductivas muestran que en el PEl de la institución A se encuentran elementos relacionados con el enfoque por competencias, pues en los fundamentos institucionales refieren aspectos como la importancia de satisfacer las necesidades del entorno y gestionar el aprendizaje significativo de los estudiantes, teniendo en cuenta la integralidad que implica la educación. Asimismo, sobre la actuación pedagógica se observa que desarrolla un modelo netamente constructivista.

Sin expresar un concepto explícito sobre competencias en la educación, el PEI refiere el enfoque de competencias como guía del proceso enseñanza-aprendizaje en la formación de los profesionales; destaca la importancia de fortalecer el desarrollo y el logro de competencias genéricas y específicas en los programas académicos, señalando que las asignaturas se organizan por competencias. La revisión muestra que el PEl de esta institución no asume una postura conceptual, ni presenta un fundamento teórico sobre competencias en la formación profesional que oriente el quehacer del programa y de los docentes en su función formadora, dejando libertad para que su comunidad académica asuma posturas diversas frente al enfoque por competencias. En consecuencia, al carecer de unicidad sobre el concepto que asume la institución, los programas y los docentes vinculados a ella no se empoderan de los lineamientos pedagógicos que ello implica.

La tendencia en la formación del profesional en el siglo XXI es por competencias, por lo que las IES deben enfatizar en su implementación, pero, según Torres (2011), aunque las IES promulgan que su modelo de formación es por competencias, a inicios de la segunda 
década del siglo XXI descuidan la fundamentación teórica y procedimental de dicho modelo. Por ello, recomienda establecer lineamientos pedagógicos de manejo de la comunidad académica para fortalecer la formación integral de los profesionales.

El PEl tampoco hace referencia a un concepto sobre competencias docentes, pero presenta una diversidad de habilidades que las equipara con las competencias que debe tener el docente vinculado, como cualificación permanente, interés por la investigación e implementación de estrategias didácticas para orientar el aprendizaje, entre otras; tampoco define u operacionaliza cada una de estas competencias, simplemente se mencionan en algunos apartes del documento. Este hecho deja libertad de interpretación y crea vacíos conceptuales para llevarlas a la práctica. Sin embargo, cabe señalar que el documento del PEI de la institución A cumple a cabalidad con los requerimientos impuestos por el MEN.

Al respecto, Barrales et al. (2012) señalan que el enfoque educativo por competencias tiene como finalidad promover una formación integral que posibilite que el estudiante desarrolle competencias en su formación profesional, pero que su implementación en la práctica no siempre es una tarea sencilla. En consecuencia, existen retos que las IES deben afrontar, como la resistencia al cambio de paradigma, pues no solo se trata de implementar una nueva metodología de trabajo académico, sino de sensibilizar a los actores con respecto a este, iniciando con la capacitación del personal docente, que debe desarrollar competencias para desempeñarse como tal. En este mismo sentido, Biesta (2012) y Bragós (2012) señalan que las IES deben establecer claramente los requerimientos para la vinculación de docentes, quienes deben poseer competencias docentes para su desempeño, tales como comprensión del funcionamiento del proceso de enseñanza-aprendizaje; planificación de la enseñanza e interacción didáctica; conocimiento teórico o disciplinar de la profesión; competencias de razonamiento, atributos y habilidades personales, profesionales e interpersonales.

Por su parte, al levantar la ficha de la institución B se encontró que el PEl expresa la importancia de resolver necesidades del entorno mediante las funciones sustantivas, al tiempo que considera que la docencia tiene como fin contextualizar los conocimientos y crear espacios de aprendizaje que sean innovadores para el aprendizaje; pedagógicamente, implementa un modelo dialogante en el que se reconocen las diversas dimensiones humanas, buscando formar integralmente al estudiante mediante el impulso del desarrollo de competencias. Asimismo, dicho PEl plantea un currículo por competencias en el que reconoce tres de los pilares de la educación: el conocer, el hacer y el ser, dejando a un lado el saber convivir, de gran trascendencia en la vida actual.

En esta línea, el Consejo Nacional de Acreditación [CNA] (2013) indica que los sistemas de pregrado avanzan en la implementación de una formación por competencias que requiere garantizar políticas de actualización y capacitación del profesorado, tanto en el ámbito de la disciplina como en el pedagógico para responder a los retos del enfoque por competencias.

La revisión documental del PEI en la institución B presenta un modelo pedagógico con base en el enfoque por competencias, asumiendo una posición conceptual: "(...) las competencias corresponden a los conocimientos, habilidades, destrezas, actitudes, comportamientos y disposiciones socio-afectivo que faculta a las personas para desempeñarse de manera efectiva ante las dimensiones en las que se desenvuelve, esto a través de seguir tres competencias, la cognitiva, la valorativa y la praxiológica, tornándolas a su vez en competencias académicas, profesionales y sociales".

El PEI no hace alusión a un concepto sobre competencias docentes específicamente, pero señala diversas competencias docentes tales como capacidad investigativa, interés por solventar problemas del entorno, por mejorar los programas académicos, por estimular al estudiante en la creación de su propio conocimiento, y por contribuir a la planeación del proceso de enseñanza-aprendizaje y el conocimiento teórico y práctico de la pedagogía. Al respecto, Valica y Rohn (2013), Soininen, Merisou y Korhonen (2013), Hernández y Luna (2013) complementan este listado con las competencias afectivas, éticas, investigativas, de creatividad e innovación, pedagógicas, de uso de las TIC, evaluativas y comunicativas.

Es posible reconocer que existe diferencia en el PEI de las dos instituciones respecto de las competencias y las competencias docentes. La institución B marca la carta de navegación de su comunidad académica respecto de la fundamentación teórica de las competencias en la educación superior y asume con claridad el enfoque por competencias como la orientación metodológica en la formación de sus profesionales. $Y$, al igual que la institución $A$, cumple con los parámetros establecidos por el MEN.

\section{Competencias docentes en el Proyecto Educativo del Programa (PEP) de Psicología, instituciones A y B}


La Universidad Nacional [UNAL] (2012) define el Plan Educativo del Programa (PEP) como el documento en el que se organizan lineamientos, principios y políticas que orientan el desarrollo del programa; además, se hacen explícitos los objetivos curriculares y la forma como se articulan con el plan de estudios. Asimismo, destaca entre los elementos del PEP los lineamientos básicos para la formación profesional, el plan de estudios, las estrategias pedagógicas y las acciones para generar articulación con el medio externo. Menciona que este documento debe presentar el perfil del personal docente para el programa, señalando sus competencias relevantes para el desempeño como formador de profesionales, elemento que debe plantearse específicamente para evitar ambigüedades.

En el PEP de Psicología la institución A se ajusta a los criterios de presentación de este, y sobre el tema objeto de investigación se destacan temas relacionados como objeto de estudio de la Psicología, perfil de ingreso y ocupacional del egresado, menciona que el perfil del docente debe estar acorde con lo estipulado en el PEI y puntualiza sobre el modelo pedagógico de tipo constructivista. No obstante, con respecto a las competencias docentes, se encontró que existen vacíos académicos y metodológicos; si bien en algunos apartados del documento se citan indirectamente cualidades que debe tener el docente del programa de Psicología, estas son muy generales.

Por su parte, el PEP de la universidad B cumple con la estructuradeestetipodedocumentosyrefierecomomodelo pedagógico el enfoque por competencias siguiendo lo establecido por el PEl, dando a conocer el diseño curricular y las estrategias metodológicas que desarrolla para llevarlo a cabo. Menciona el perfil que deben poseer los docentes vinculados al programa, señalando sus derechos y deberes y señala entre las competencias docentes la capacitación permanente, buena comunicación con el estudiante, conocimientos de la disciplina y capacidad investigadora, sin asumir un concepto teórico ni especificar lineamientos metodológicos para su desarrollo en la formación del psicólogo.

Al respecto, la Organización para la Cooperación y el Desarrollo Económico [OCDE] (2010) plantea que el desarrollo de los programas de formación profesional necesita competencias que habiliten a los jóvenes a entrar directamente al mercado laboral, pero también les permita continuar su formación en el futuro; sugiere que esto se puede lograr a través de una formación profesional de calidad, llevada a cabo mediante un plan educativo del programa con claros lineamientos pedagógicos, investigativos y de proyección a la sociedad, que marque la ruta a seguir por docentes capacitados en el enfoque por competencias y con una clara orientación metodológica en los lineamientos pedagógicos de cada programa.

\section{Competencias docentes en el Estatuto docente, instituciones A y B}

El Estatuto Docente, según el MEN (2002) en el Decreto 1278, tiene por función regular las relaciones de los docentes con el Estado y con las IES a las que se encuentran vinculados, para garantizar que el ejercicio docente sea de calidad, y a su vez se reconozca su desempeño, experiencia, formación y competencias como los atributos esenciales en todo lo concerniente al desarrollo como profesionales de la docencia. Sobre las competencias docentes refiere temas conexos como los derechos a los que pueden acceder en su profesión, destacando los estímulos para la superación y la eficiencia, y la permanencia en sus cargos siempre y cuando su labor sea realizada con idoneidad. Este documento indica que los docentes tienen derecho a formación, capacitación y actualización y destaca los principios y valores que fundamentan la profesión docente. También destaca entre sus derechos: autodesarrollo, autonomía, comunicación, solidaridad, responsabilidad, honestidad, conocimiento, justicia, transparencia y respeto. Entre los deberes del docente están los estímulos para la formación académica, la investigación y la innovación. Sobresale el mejoramiento de procesos educativos y la orientación del aprendizaje de los educandos, elementos estos que se relacionan de alguna forma con las competencias docentes.

Denominado en la institución A Reglamento de Educadores Profesionales, propende por la calidad del ejercicio y el desempeño del docente, señalando que el docente debe planificar, organizar, desarrollar y evaluar todas las actividades que están relacionadas con su ejercicio profesional como formador de profesionales; expone los derechos que tienen los educadores a la profesionalización constante y a recibir incentivos por su trabajo; y considera que el ejercicio de la docencia tiene como base el autodesarrollo, la autonomía y la comunicación, entre otros.

La ficha de revisión de este reglamento en los temas referidos a las competencias docentes muestra la necesidad de que los docentes vinculados a la institución A evidencien estudios de profundización en su área de conocimiento específica; las funciones que debe cumplir y los incentivos que reciben por su actividad académica; al mismo tiempo lista diferentes aspectos que pueden clasificarse como competencias docentes: compromiso ético, formación pedagógica, formación investigativa 
y capacidad creativa en la creación de ambientes de aprendizaje.

Por su parte, el Estatuto docente de la institución $B$, respecto de las competencias docentes y la ficha de revisión, expone aspectos concernientes a la profundización académica que deben acreditar los educadores; así mismo, los derechos y deberes a los que puede acceder el docente que pertenece a esta institución, y resalta la importancia de promover actividades académicas en beneficio del desempeño e interés por la preparación académica, y la actitud reflexiva y comunicativa.

La reflexión acerca de los resultados encontrados en el Estatuto docente respecto de las competencias que debe tener un profesor universitario es muy limitada; su contenido es más de tipo legal que académico o pedagógico, por lo que hace falta asumir una concepción de docencia, de ejercicio docente y de competencias docentes que le brinden a la comunidad académica, particularmente a los docentes vinculados los lineamientos necesarios para que asuman con claridad sus responsabilidades en la formación de profesionales desde la docencia, la investigación y la proyección al entorno.

\section{¿Qué conocen y cómo asumen los docentes los lineamientos institucionales?}

Los docentes adscritos a los programas de Psicología de las universidades que participaron en el estudio respondieron a tres preguntas, sintetizadas en: ¿conoce las competencias docentes que se encentran planteadas en el PEl, en el PEP (del programa de Psicología) y en el Estatuto docente de la institución? Los resultados se sintetizan en la Tabla 1.

La realidad expresada en la Tabla 1 es preocupante, porque los docentes no tienen conocimiento de los lineamientos

\section{Tabla 1}

Conocimiento del docente de los programas de Psicología sobre competencias docentes que se registran en el PEI, PEP y el Estatuto Docente de su universidad

\begin{tabular}{|c|c|c|c|}
\hline IES & $\begin{array}{c}\text { Competencias docentes } \\
\text { PEI }\end{array}$ & $\begin{array}{c}\text { Competencias docentes } \\
\text { Estatuto Docente }\end{array}$ & Competencias docentes PEP \\
\hline \multirow[t]{2}{*}{$\mathbf{A}$} & $\begin{array}{l}\text { - Capacitación intelectual } \\
\text { - Capacidad de razonamiento } \\
\text { - Lecto-escritora } \\
\text { - Ciudadanas } \\
\text { - Filosofía institucional } \\
\text { - Metodológicas } \\
\text { - Formación humana } \\
\text { - La fe, la ciencia y la cultura } \\
\text { - Investigativas }\end{array}$ & $\begin{array}{l}\text { - Cognitivas actitudinales e } \\
\text { investigativas } \\
\text { - Empatía y escucha } \\
\text { - El ser, el hacer y el conocer. } \\
\text { - Las mismas del PEl } \\
\text { - No tiene que ver con competencias } \\
\text { es sobre aspectos legales }\end{array}$ & $\begin{array}{l}\text { - Cognitivas y actitudinales } \\
\text { - Argumentativas e interpretativas. } \\
\text { - Iguales a las de los estudiantes } \\
\text { - Para motivar el aprendizaje } \\
\text { - Facilitadoras del conocimiento. } \\
\text { - Ética } \\
\text { - Este documento no trata de } \\
\text { competencias docentes }\end{array}$ \\
\hline & $\begin{array}{l}4 \text { de los } 8 \text { docentes dicen no conocer } \\
\text { el PEI }\end{array}$ & $\begin{array}{l}5 \text { de los } 8 \text { docentes dicen no conocer el } \\
\text { Estatuto docente }\end{array}$ & $\begin{array}{l}4 \text { de los } 8 \text { docentes dicen no conocer el } \\
\text { PEP }\end{array}$ \\
\hline B & $\begin{array}{l}\text { - Habla sobre el enfoque por } \\
\text { competencias } \\
\text { - Formación humana } \\
\text { - Mejora de procesos educativos } \\
3 \text { de los } 5 \text { docentes dicen no conocer } \\
\text { el PEI }\end{array}$ & $\begin{array}{l}\text { - Refieren no tener conocimientos } \\
\text { sobre este documento }\end{array}$ & $\begin{array}{l}\text { - Refieren no tener conocimientos sobre } \\
\text { este documento. }\end{array}$ \\
\hline
\end{tabular}

Fuente: Autores

básicos de la institución a la cual se encuentran vinculados para apoyar la formación del psicólogo competente para el siglo XXI. Cuantitativamente, 7 de los 13 docentes entrevistados (54\%) desconocen la existencia del PEl; 10 docentes (77\%) desconocen la existencia del Estatuto Docente y 9 no conocen el PEP del programa de Psicología de la institución donde trabajan. Es de anotar que quienes contestan listando algunas competencias que dicen estar registradas en cada uno de estos tres documentos objeto de estudio no lo hacen con la convicción de conocer, sino desde su propia experiencia docente; es por ello que no se encuentra relación entre las respuestas dadas por los docentes y los resultados que arrojó la revisión documental del PEl, del PEP y del 
Estatuto docente de las instituciones objeto de estudio.

En conclusión, los 13 docentes de los programas de psicología de las dos instituciones que hicieron parte de este estudio no se acercan a estos documentos para apropiarse de ellos ni de los lineamientos teóricos y metodológicos que fundamentan el quehacer de la institución y del programa de Psicología. Mejor, su fundamentación teórica y su praxis sobre las competencias docentes no tienen base conceptual en el $\mathrm{PEI}$, en el PEP, ni en el Estatuto docente. En la práctica, los procesos y procedimientos que llevan a cabo en su labor tienen elementos de estos lineamientos por las exigencias instrumentales que deben cumplir con el programa y por tanto con la institución, pero la práctica en el aula se realiza desde la concepción de cada docente de manera individual.

Las respuestas que ofrecen los docentes entrevistados en relación con las competencias docentes (que se señalan en los tres documentos) son muy vagas $y$ demasiado generales, no puntualizan ni especifican sobre el tema. Fuera de la entrevista, la mayoría de los docentes comentó que solamente una vez el vicerrector académico (institución A) y el decano (institución B) presentaron el PEI en reuniones de docentes o que, como parte de la inducción docente de un semestre, se socializó el PEl y el PEP. Pero, según el Ministerio de Educación Nacional (1994a), el PEl es un instrumento que explicita y comunica una propuesta integral para orientar de modo coherente e integrado los procesos de intervención educativa que desarrolla la institución, por lo que debe ser de conocimiento y manejo permanente de su comunidad académica.

Por su parte, el Ministerio de Educación Nacional (1994a), en la Ley 115 , dice que el PEI debe responder a situaciones y necesidades de los educandos, de la comunidad local, la región y el país; y ser concreto, factible y evaluable. En las instituciones A y B esto no se cumple, porque los docentes encargados de la formación lo desconocen; por tanto, no pueden conceptuar sobre su factibilidad y no han participan en su evaluación. Se supone que el PEI es una construcción permanente desde la participación mancomunada de la comunidad académica, pero en este caso no se evidencia esta dinámica de construcción.

El Proyecto Educativo Institucional es concebido por la Universidad del Rosario $(2014,1 \mathrm{~m})$ como la carta de navegación que orienta el desarrollo de las funciones sustantivas de docencia, investigación y extensión, en el marco de su misión, visión y valores; orienta y soporta las acciones educativas con el propósito de favorecer la formación integral de sus estudiantes, a la luz de calidad, excelencia e identidad y de actividades centradas en el estudiante, orientadas a construir el conocimientos, la producción científica y la integración con el entorno. Si es una carta de navegación, debe ser conocido y manejado por el equipo de trabajo, y los administrativos académicos, los docentes y los estudiantes deben asumirlo para responsabilizarse de su cumplimiento.

Se halló que los docentes de las instituciones A y B desconocen los lineamientos fundamentales de la institución y del programa; al respecto puntualiza Calvo (1995) que la comunidad educativa requiere saber que el PEI comienza escribiendo el documento, producto de un diálogo y una negociación de todos, y responde a los postulados de una pragmática comunicativa, por tanto, debe ser conocido, cuestionado y verificado. Dice la autora que pensar que el PEl es un documento para cumplir y archivar es pensar el PEI bajo una óptica instrumental que poco o nada aporta a la calidad educativa; pues las instituciones que actúan bajo el cumplimiento solo de la norma, no superan el nivel heterónomo de la gestión, y en tal sentido no hacen uso del PEI como posibilidad de reivindicación de la autonomía de los procesos pedagógicos a partir del sentir de los actores. El MEN (1994b) añade que el PEI debe ser una construcción colectiva que comprometa a la comunidad educativa.

Solamente si es construcción colectiva, dice Peña (1995), el PEI podrá dibujar el mapa por el que la comunidad educativa camine hacia el futuro; caso contrario, los docentes seguirán trabajando desde proyectos pedagógicos de aula, es decir, individualmente.

También es preocupante que los docentes del programa de Psicología desconozcan el Proyecto Educativo del Programa (PEP) al que se encuentran vinculados. La Universidad de Antioquia (2011) señala que el PEP debe ser elaborado con la participación de toda la comunidad educativa del programa, teniendo en cuenta a los egresados y a los empleadores. En dicho documento se explicita cómo los programas académicos asumen las perspectivas tanto disciplinares como profesionales y se insertan en el PEl. Cuando el docente no se apropia de los lineamientos pedagógicos, metodológicos, investigativos y de proyección de su programa, es de suponer que cada uno funciona de manera independiente según sus criterios, desde los que aporta a la formación del psicólogo.

Cabe destacar que el PEP se debe ajustar a la normatividad existente, en el caso del programa de Psicología, a las disposiciones del MEN, de la Comisión Nacional de Aseguramiento de la calidad de la Educación Superior 
[Conaces], del Instituto Colombiano para el Fomento de la Educación Superior [lcfes], del Consejo Nacional de Acreditación [CNA], de la Asociación Colombiana de Facultades de Psicología [Ascofapsi] y del Colegio Colombianos de Psicólogos [Colpsic], a las normas institucionales sobre temas afines y a las revisiones permanentes del estado de la cuestión de la formación de psicólogo producidas por comunidades académicas a nivel nacional e internacional. En sus PEP, los programas de Psicología de las instituciones Ay B se ajustan a estas normas, pero específicamente sobre el tema de competencias docentes existen vacíos conceptuales y prácticos.

Sobre el Estatuto docente, otro de los lineamientos que tienen que ver directamente con la relación del docente y la institución, es clara la reflexión de que el Estatuto docente regula su relación con la institución a la que se encuentra vinculado profesionalmente y por tanto debe ser de su conocimiento y manejo; pero, esto no sucede con los docentes de los programas de Psicología de las instituciones A y B; los docentes, principalmente de la institución $B$, no se interesan por esta normatividad que da lineamientos sobre su desempeño en la docencia; por tanto, desconocen las competencias que la institución exige para su vinculación y posterior desempeño; de la misma forma, desconocen sus derechos y sus deberes como docentes de la institución, los niveles o categorías a las que puede acceder y cómo hacerlo, entre otras.

El MEN (2002) en el decreto 1278, determina que la función docente implica la realización directa de los procesos sistemáticos de enseñanza-aprendizaje, lo cual incluye el diagnóstico, la planificación, la ejecución y la evaluación de los dichos procesos y sus resultados dentro del marco del PEl. Siendo indiscutible que la institución, además de evidenciar la existencia del Estatuto docente, debe socializarlo y entregarlo a los docentes para que asuman su compromiso profesional con la institución. La Universidad Sergio Arboleda (2013) concluye en que la elaboración del Estatuto docente significó trabajo mancomunado de su comunidad académica, principalmente de los docentes, quienes deben conocerlo y manejarlo.

\section{Conclusiones}

El enfoque por competencias es la tendencia en la formación de profesionales del siglo XXI que las IES están empeñadas en implementar, esto con la finalidad de aportar significativamente a la formación de profesionales integrales y competentes para transformar las realidades, tanto en el campo científico como en la sociedad. Para ello es necesario que las IES se muden de un paradigma lineal propio de la educación tradicional a uno que les permita avizorar y percibir el mundo real para el cual están formando profesionales. En consonancia, el docente universitario tiene la obligación de cambiar su "chip", lleno de postulados de educación memorística, repetitiva y lineal por un paradigma donde la educación se asume dinámica en tanto el conocimiento está en todas partes y el docente no es el poseedor de este, sino que tienen la posibilidad de orientar la creación del conocimiento por parte del estudiante. El cambio de paradigma es una excelente posibilidad para que las IES, y con ellas los docentes, reflexionen críticamente sobre su responsabilidad en la formación de profesionales competentes.

En la realidad contextual de las instituciones $A$ y $B$ objeto de este estudio no se está implementando la formación por competencias a cabalidad, ya que no están dadas las condiciones debido a que no cambiaron de paradigma y decidieron adoptar el enfoque de competencias como su "modelo educativo", al tiempo que continúan con una visión de mundo estática e idílica; un concepto pasivo de educación: un proceso de aprendizaje en el que el docente enseña y el estudiante aprende; un estamento docente sin competencias docentes, con asignaciones académicas elevadas y un mínimo de tiempo para el desarrollo de competencias en los estudiantes; con responsabilidades en la función investigativa, pero sin la competencia investigadora, los recursos necesarios, ni el tiempo disponible para desarrollar proyectos que aporten al avance de la ciencia y al avance de la sociedad; con responsabilidades administrativas que los alejan de su función como docentes.

Conviene reconocer que para un desempeño docente de calidad se requiere, además de las competencias docentes, de la confluencia de los factores que lo condicionan y los atributos que lo caracterizan, como son la infraestructura física, tecnológica, administrativa, investigativa, académica, curricular y de extensión, entre otros. En consecuencia, es indispensable conocer cómo los lineamientos pedagógicos institucionales son asumidos por el docente en su labor de orientar el logro de las competencias de los profesionales de la Psicología.

El PEl, el PEP y el Estatuto docente son documentos institucionales que marcan lineamientos sobre los cuales funcionan la institución y el programa académico para dar cumplimiento a su misión educativa: Se consideran la carta de navegación, pero no contemplan -o lo hacen de manera muy general-las competencias docentes que deben tener para aportar significativamente a la formación del psicólogo.

El PEl, el PEP y el Estatuto docente son documentos evidenciados por las instituciones objeto de estudio, 
pero no son conocidos ni manejados por la comunidad educativa, en el caso concreto de los docentes de los programas de psicología analizados. Por tal razón, los lineamientos consignados en ellos no son asumidos por los docentes en su desempeño. De ahí que sea indispensable que en los procesos de calidad a los que se someten las IES se construyan espacios de reflexión crítica frente a los lineamientos pedagógicos necesarios para formar psicólogos bajo el enfoque de competencias, lineamiento que debe formar parte de un ejercicio participativo que permita construir una comunidad académica donde el docente es factor fundante $y$, por tanto, principal constructor de la teoría y la práctica de su ejercicio como formador del psicólogo capaz de transformar la realidad y aportar al mejoramiento de la calidad de vida de los seres humanos.

\section{Agradecimientos}

Los autores agradecen a las instituciones que contribuyeron a la realización de la investigación de la que da cuenta este artículo. A los programas académicos a los que están vinculados los investigadores por la asignación del tiempo necesario, y a las IES y docentes de los programas de Psicología que participaron voluntariamente en el estudio.

\section{Referencias}

Arias, F. (2006). El proyecto de investigación. Introducción a la metodología científica. Caracas: Epísteme.

Beata, G. (2014). School in the Era of the internet. Edu. Educ., 17(1), 171 - 180.

Barrales, A., Villalobos, M., Landín, M., Pérez, M., Cruz, I. \& Rodríguez, A. (2012). El enfoque educativo basado en competencias, un reto que enfrenta la Universidad Veracruzana. Educación, 21(41), 23-39.

Beneitone, P., Esquetini, C., González, J., Marty, M., Siufi, G. \& Wagenaar, R. (2007). Reflexiones y perspectivas de la Educación Superior en América Latina. (Informe Final -Proyecto Tuning- América Latina 2004-2007). Bilbao: Universidad de Deusto y Universidad de Groningen.

Bericat, E. (1998). La integración de los métodos cuantitativo y cualitativo en la investigación social. Barcelona: Ariel.

Biesta, G. (2012). The future of teacher education: Evidence, competence or wisdom? ROSE. Research on Steiner Education, 3(1), 8-21.

Bonilla, C. \& Rodríguez, S. (1997). Más allá del dilema de los métodos en la investigación en ciencias sociales. Bogotá: Ediciones Uniandes.

Bragós, R. (2012). Las competencias del profesorado en el entorno CDIO. REDU. Revista de Docencia Universitaria, 10(2), 57-73.
Calvo, G. (1995). Los proyectos educativos institucionales y la formación de docentes. (Ponencia presentada en el seminario sobre Nuevas formas de enseñar y de aprender). Santiago: Orealc-Unesco.

Camelo, E. (2014). Modelo de formación del profesorado en tecnología educativa. I+ D Revista de Investigaciones, 3(1), 18-23. Recuperado de https:// doi.org/10.33304/revinv.v03n1-2014002

Consejo Nacional de Acreditación. (2013). Lineamientos para la acreditación de programas de pregrado. Recuperado de https://www.cna.gov.co/1741/ articles-186359_pregrado_2013.pdf

Delors, J. (1996). La educación encierra un tesoro. (Informe a la Unesco de la Comisión Internacional sobre la Educación para el Siglo XXI). Madrid: Santilla Ediciones.

García, S. \& González, J. (2015). La universidad educa para la libertad. Reflexiones de un humanismo personalista. I+D. Revista de Investigaciones, 5(1), 108123. Recuperado de https://doi.org/10.33304/revinv. v05n1-2015007

Giné, N. (2008). Cómo mejorar la docencia universitaria: el punto de vista del estudiantado. Revista Complutense de Educación, 20(1), 117-134.

Gómez, M. \& Alzate, M. (2010). La alegre entrada y el irresistible ascenso de las competencias en la universidad. Educ.Educ., 13(3), 453-474.

Gorden, R. (1969). Interviewing. Strategy, techniques and tactics. Homewood: Dorsey Press.

Guzmán, A. \& Gutiérrez, C. (2017). Las competencias digitales y el uso de las tecnologías sociales: el valor agregado en la comercialización en el sector calzado en Bucaramanga. I+D Revista de Investigaciones, 11(1), año 6, 17-27. Recuperado de https://doi. org/10.33304/revinv.v11n1-2018002

Hernández, I. \& Luna, S. (2013). Creación e innovación: estrategia de competitividad regional. En: I. Hernández y L. S. Pemberthy (Ed.), UniversidadEmpresa-Estado: hacia la cultura de la investigación y la innovación (pp. 187-199). Bogotá: Ediciones Universidad Cooperativa de Colombia.

Hernández, I., Alvarado, J. \& Luna, M. (2015). Creatividade innovación: competencias genéricas o transversales en la formación profesional. Revista Virtual Universidad Católica del Norte, 1(44), 135-151.

Hernández, I., Recalde, J. \& Luna, J. (2015). Estrategia didáctica una competencia docente en la formación para el mundo laboral. Revista Latinoamericana de Estudios Educativos, 11(1), 73-94.

Irigoyen, J., Jiménez, M. \& Acuña, K. (2011). Competencias y educación superior. Revista Mexicana de Investigación Educativa, 16(48), 243-266.

Martínez, J. (2011). Metodologías de la investigación cualitativa. Silogismo más que conceptos, 8 (1), 27-38. 
Ministerio de Educación Nacional, (1994a). Ley 115. Por la cual se expide la ley general de educación. Recuperado de http://www.mineducacion.gov. co/1621/articles-85906_archivo_pdf.pdf

Ministerio de Educación Nacional. (1994b). Decreto 1860, por el cual se reglamenta parcialmente la Ley 115 de 1994, en los aspectos pedagógicos y organizativos generales. Recuperado de http://www.mineducacion. gov.co/1621/articles-86240_archivo_pdf.pdf

Ministerio de Educación Nacional. (2002). Decreto 1278 de junio 19 de 2002 por el cual se expide el Estatuto de Profesionalización Docente. Recuperado de: http:// www.mineducacion.gov.co/1621/articles-86102_ archivo_pdf.pdf

Ministerio de Educación Nacional. (2003). Decreto 2566 por el cual se establecen las condiciones mínimas de calidad y demás requisitos para el ofrecimiento y desarrollo de programas académicos de educación superior y se dictan otras disposiciones. Recuperado de http://www.mineducacion.gov.co/1621/ articles-86425_Archivo_pdf.pd

Ministerio de Educación Nacional. (2014). Módulo del Proyecto Educativo Institucional (PEI). Recuperado de http://www.modernizacionsecretarias.gov.co/ images/documents/Archivo/Manualdeusuario/ Manuales\%20SIGCE/MEN/20140224-SIGCE\%20 Manual\%20MEN-PEI\%20v_1_1.pdf

Ministerio de Educación Nacional, (2015). Decreto 1075, Se expide el Decreto Reglamentario Único del Sector Educativo. Recuperado de http:// www.mineducacion.gov.co/normatividad/1753/ articles-351080_recurso_1.pdf

Morales, R. \& Cabrera, J. (2012). Competencias docentes transversales, el método de selección. Mi Zona-CDT. REDU Revista de Docencia Universitaria, 10(2), 75-101

Morín, E. (2007). La cabeza bien puesta. (Mahler, P. Trad.). Buenos Aires: Ediciones Buena Visión.

Organización para la Cooperación y el Desarrollo Económico. (2010). Panorama de la educación 2010: Indicadores de la OCDE. Recuperado de https://www.oecd.org/education/skills-beyondschool/45925316.pdf

Peña, L. (1995). El Proyecto Educativo Institucional es una construcción social. Alegría de Enseñar, 22, 8 - 9.

Salgado, E. (2006). Manual de docencia universitaria introducción al constructivismo en la educación superior. Costa Rica: ULACIT.

Soininen, M., Merisuo, T. \& Korhonen, R. (2013). What kind of competence teachers need in the year 2020? Profesorado revista de Curriculum y Formación del Profesorado, 17(3), 111-122.

Tejada, F. (2009). Competencias docentes. Profesorado Revista de Currículum y Formación del Profesorado, 13(2), 1-15.
Torres, G. (2011). Las competencias de los psicólogos en Colombia y en el mundo. (Tesis de maestría en Pedagogía). Universidad de La Sabana. Recuperado de http://www.ascofapsi.org.co/portal/archivos/ Tesis_German_Torres.pdf

Universidad de Antioquia (2011). Proyecto Educativo del Programa (PEP). Recuperado de http:// ww w.udea.edu.co/wps/wcm/connect/ udea/375ff903-aff2-4d68-883b-5d9650e65f01/ Proyecto+Educativo+del+Programa+-PEP-+Jul. pdf?MOD=AJPERES

Universidad del Rosario. (2014). Proyecto Educativo Institucional. Bogotá: Editorial Universidad del Rosario.

Universidad Nacional de Colombia. (2012). Guía para consolidar el Proyecto Educativo del Programa -PEPautoevaluación y seguimiento de la calidad de los programas de pregrado. Recuperado de http://www. pregrado.unal.edu.co/docs/acreditacion/general/ Guia_PEP_2012.pdf

Universidad Sergio Arboleda. (2013). Estatuto Docente. Recuperado de https://www.usergioarboleda.edu. co/institucional/\#estatuto_docente

Valica, M. \& Rohn, T. (2013). Development of the professional competence in the ethics teachers. Procedia Social and Behavorial Sciences, 106, 865-872.

Vásquez, H. (1986). Los intereses de la vida cotidiana y las ciencias. Universidad Nacional de Colombia. 